\title{
ARTIGOS
}

Submetido 13.07.2016. Aprovado 09.05.2017

Avaliado pelo processo de double blind Review. Editores Científicos: Felipe Zambaldi e Aron Belinky

DOI:http://dx.doi.org/10.1590/S0034-759020170505

\section{ACORDO SETORIAL DE EMBALAGEM: AVALIAÇÃO À LUZ DA RESPONSABILIDADE ESTENDIDA DO PRODUTOR}

\author{
Sectoral agreement on packaging: Assessment based on extended producer \\ responsibility
}

\author{
Acuerdo sectorial de envases: Evaluación a la luz de la responsabilidad extendida del \\ productor
}

\begin{abstract}
RESUMO
Esta pesquisa tem como objetivo discutir os impactos do acordo setorial de embalagens na cadeia de reciclagem brasileira e no design de embalagens à luz dos princípios da Responsabilidade Estendida do Produtor (RPE). A metodologia empregou análise documental e entrevistas em profundidade com múltiplos stakeholders, incluindo representantes dos setores público, privado e cooperativas de catadores. A análise de conteúdo foi utilizada para avaliação e interpretação dos dados coletados. As conclusões apontam para uma expansão da coleta de recicláveis, com potenciais benefícios para geração de renda em cooperativas, porém com nenhum impacto no processo de desenvolvimento de produtos e embalagens mais sustentáveis de maneira efetiva. A ausência de metas individuais possibilita que as empresas cumpram a legislação a custos bastante reduzidos. A proposta apresentada, ao tratar embalagens de características diferentes de maneira uniforme, somada ao paradigma de desenvolvimento de embalagens que privilegia a competitividade em detrimento da reciclabilidade, compromete os resultados prometidos pelo acordo setorial.
\end{abstract}

PALAVRAS-CHAVE | Acordos setoriais, logística reversa, embalagens, catadores, responsabilidade do produtor.

\begin{abstract}
This study discusses the impact of the packaging sectoral agreement in the Brazilian recycling chain and packaging design under the principles of Extended Producer Responsibility (EPR). The study uses document analysis and interviews with multiple stakeholders, including representatives of the public sector, private sector, and recycling cooperatives. Content analysis was used to analyze and interpret the data collected. The findings point to expanding the collection of recyclables, with potential benefits for income generation in cooperatives, but with no impact on the process of effectively developing more sustainable products and packaging. The absence of individual targets provides an alternative for companies to comply with the legislation through very reduced costs. The proposal related to managing packs of different features equally, and the packaging development paradigm that focuses on competitiveness at the expense of recyclability, commits the results promised by the sectoral agreement.
\end{abstract}

KEYWORDS / Sectoral agreement, reverse logistics, packaging, waste pickers, producer responsibility.

\section{RESUMEN}

\section{JACQUES DEMAJOROVIC}

jacquesd@fei.edu.br

Professor do Centro Universitário da FEl, Departamento de

Administração - São Paulo - SP, Brasil

\section{BRUNO MASSOTE}

bmassote@gmail.com Mestre em Administração pelo

Centro Universitário da FEI, Departamento de Administração São Paulo - SP, Brasil
Esta investigación tiene como objetivo discutir los impactos del acuerdo sectorial de envases en la cadena de reciclaje brasileña y en el diseño de envases a la luz de los principios de la Responsabilidad Extendida del Productor (RPE). La metodología empleada fue análisis documental y entrevistas en profundidad con múltiples stakeholders, incluyendo representantes de los sectores público, privado y cooperativas de recolectores. Para la evaluación e interpretación de los datos recolectados se utilizó el análisis de contenido. Las conclusiones apuntan hacia una expansión de la recolección de reciclables, con potenciales beneficios para la generación de ingresos en las cooperativas, no obstante, sin ningún impacto en el proceso de desarrollo de productos y envases más sostenibles de manera efectiva. La ausencia de metas individuales posibilita que las empresas cumplan la legislación a costos bastante reducidos. La propuesta presentada, al tratar envases de características diferentes de manera uniforme, sumada al paradigma de desarrollo de envases que privilegia la competitividad en detrimento de la reciclabilidad, compromete los resultados prometidos por el acuerdo sectorial.

PALABRAS CLAVE / Acuerdos sectoriales, logística reversa, envases, recolectores, responsabilidad del productor. 


\section{INTRODUÇÃO}

O conceito de Responsabilidade Estendida do Produtor (REP) surge como um princípio transformador fundamental na busca de um padrão de produção e consumo mais sustentável. Tojo (2004) destaca, como principais características da REP, a ênfase nas medidas de prevenção em vez de medidas de contenção, o fortalecimento da visão sistêmica sobre todo o ciclo de vida e a substituição de medidas de comando e controle por uma abordagem focada em metas de redução do impacto ambiental. A responsabilidade pela gestão dos resíduos pós-consumo, antes atribuída aos consumidores e à administração pública, passa a incluir parcialmente ou integralmente os fabricantes desses produtos. Como resultado, espera-se que o próprio fabricante influencie o processo de evolução de design de embalagens e produtos de modo a reduzir o impacto ambiental causado por eles no final do seu ciclo de vida (Atasu \& Wassenhove, 2012; Thorpe, Kruszewska, \& McPherson, 2004; Toffel, Stein, \& Lee, 2008). No entanto, pesquisas sobre a efetividade da REP como indutor de inovação tecnológica de materiais favorecendo o ecodesign não são conclusivas (Røine \& Lee, 2006; Sluisveld \& Worrel, 2013).

No Brasil, a responsabilidade dos produtores sobre seus resíduos pós-consumo ganhou força com a aprovação da Política Nacional de Resíduos Sólidos (PNRS, 2010), que inclui uma série de instrumentos inovadores, como a responsabilidade compartilhada, de modo a assegurar coleta e destinação correta dos resíduos pós-consumo, a exigência de um Acordo Setorial (AS) e a inclusão das cooperativas de catadores como fornecedores de serviços na cadeia reversa (Demajorovic, Zuñiga, Boueres, Silva, \& Sotano, 2012; Gomes, Oliveira, Brescian, \& Pereira, 2014; Jesus \& Barbieri, 2013). Em seus princípios e objetivos, a lei também avança em questões fundamentais como o instrumento do protetor recebedor, a visão sistêmica na gestão de resíduos sólidos, estímulo à produção e consumo sustentáveis e avaliação do ciclo de vida de produto (Batista, 2015; Jacobi \& Besen, 2011). Em 2015, a coalizão, criada em 2012 e liderada pelo Compromisso Empresarial para a Reciclagem (Cempre), assinou o AS de Embalagens atendendo à exigência da PNRS. 0 acordo prevê a expansão da coleta seletiva no País, ampliando o índice de reciclagem de embalagens, e encaminhamento da maior parte desse material para cooperativas de catadores (Sistema Nacional de Informações sobre a Gestão de Resíduos Sólidos [Sinir], 2015). Tema recente no País, poucos artigos se debruçaram sobre os impactos na cadeia produtiva de embalagens em função da nova legislação e dos acordos setoriais firmados. A expansão esperada a partir do AS suscita questões importantes, tais como: Qual é o impacto dessa ampliação da coleta no desempenho da cadeia reversa de embalagens ( $Q \mathrm{QP}_{1}$ ) e como o AS, ao exigir de fabricantes a implementação da Logística Reversa (LR), favorecerá o processo de reciclabilidade de materiais, potencializando a atividade de reciclagem (QP2). Considerando a lacuna na literatura nesse campo, esta pesquisa tem como objetivo discutir os impactos do AS de embalagens na cadeia de reciclagem brasileira e no design de embalagens à luz dos princípios da REP.

\section{RESPONSABILIDADE ESTENDIDA DO PRODUTOR}

A REP assume como premissa que qualquer fabricante que coloque embalagens no mercado passa a ser responsável pelo gerenciamento e recuperação delas após o descarte, por meio do desenvolvimento de um sistema de logística reversa. A LR é definida como o processo de planejamento e implementação de um fluxo reverso que garanta o reaproveitamento dos produtos pós-consumo com objetivo de agregar valor ou efetuar o descarte de maneira correta (Rogers \& Tibben-Lembke, 1998; Rubio, Chamorro, \& Miranda, 2008). As opções para o cumprimento dessa responsabilidade incluem a implementação de sistemas individualizados ou coletivos, podendo, a partir de aprovação de autoridades locais, ser gerenciados diretamente pelas empresas ou transferidos para outra entidade incumbida de gerenciar o processo (Cruz, Ferreira, Cabral, Simão, \& Marques, 2014).

O sistema Ponto Verde, na Alemanha, ou o Nedvang, na Holanda, são exemplos de sistemas compartilhados em que os fabricantes de produtos embalados contribuem com recursos financeiros e transferem automaticamente a responsabilidade pela gestão e recuperação das embalagens para entidades gestoras (Atasu, Wassenhove, \& Sarvary, 2009). Os recursos são normalmente garantidos por taxas de reciclagem já embutidas nos preços finais dos produtos e devem ser aplicados nos processos de coleta seletiva e separação das embalagens. Além de financiar a atividade, as taxas têm como objetivo influenciar o comportamento de fabricantes e consumidores ao afetar o preço final do produto. Brouillat e Oltra (2012) concluíram, por meio de um modelo de simulação que considera as interações entre empresas, consumidores e recicladores, que as taxas de reciclagem só produzem efeito significativo se forem individualizadas e cobradas proporcionalmente à reciclabilidade do resíduo gerado por cada produtor. 0 modelo francês é um bom exemplo desse funcionamento. Enquanto usuários de embalagens de vidro pagam uma taxa de 4 euros por tonelada colocada no mercado, os usuários de plástico pagam uma taxa de 222 euros por tonelada (Pro-Europe, 2010). Como resultado, fabricantes 
são incentivados a investir em P\&D de modo a utilizar em suas embalagens materiais que gerem menos danos ambientais e favoreçam a reciclabilidade, assegurando sua competividade (Thorpe et al., 2004).

O mesmo fenômeno não acontece nos programas com metas coletivas. Caso um fabricante pertencente a um acordo coletivo resolva inovar desenvolvendo embalagens com maior reciclabilidade, eventuais reduções de custos serão diluídas pelos integrantes do acordo coletivo. Assim, apenas uma pequena fração do benefício gerado pela inovação será efetivamente transferida ao fabricante que a desenvolveu, desestimulando o investimento nesse processo (Organisation for Economic Co-operation and Developmen [OECD], 2005). Para Kalimo, Lifset, Rossem e Mayers (2012), os acordos coletivos facilitam também o aparecimento dos chamados caroneiros ou free-riders, que, se beneficiando das brechas oferecidas por essa alternativa, colocam suas embalagens no mercado sem pagar as taxas para as entidades gerenciadoras dos programas de REP. Como consequência, podem oferecer seus produtos a preços mais baixos no mercado, gerando desequilíbrio econômico em alguns setores e onerando os sistemas de coleta de resíduos pós-consumo (Lifset \& Lindhqvist, 2008). Para os autores, somente a responsabilidade individual, somada à imposição de custos diferenciados aos fabricantes em função dos materiais utilizados na composição de embalagens e produtos, pode favorecer a reciclabilidade.

Lambert (2012) contrapõe a percepção de que somente a responsabilização individual fomentará o ecodesign ao analisar seis estudos de caso de empresas de eletroeletrônicos na Europa. Um dos exemplos analisados é o da empresa HP, que, para atender à legislação vigente no setor de eletroeletrônicos, juntou-se à Sony, Electrolux e Braun em um acordo coletivo. A solução conjunta permitiu que, em 2012, a empresa recuperasse 120 mil toneladas de produtos eletrônicos que foram utilizados como matéria-prima para a produção de 800 milhões de cartuchos para impressoras. Como ressalva, não há informação disponível de quanto esse montante representa em relação ao total produzido pela empresa.

Os debates sobre a REP têm focado também os resultados efetivos alcançados. Cahill, Grimes e Wilson (2010) mostram, em uma pesquisa em 11 países europeus, que apenas a Inglaterra não cumpriu a meta de recuperação de 50\% das embalagens, sendo que os demais países atingiram a meta ou mesmo a superaram. Para os autores, países onde as autoridades locais participaram ativamente do processo de desenho e implantação dos sistemas de coleta, e também nos investimentos em infraestrutura, apresentaram resultados mais expressivos do que países com menor envolvimento do setor público.
Já o estudo de Røine e Lee (2006) focou o impacto da REP nos setores de embalagens plásticas e eletroeletrônicos na Noruega e seu efeito sobre o processo de inovação tecnológica de materiais. A redução do custo da embalagem foi mencionada por $48 \%$ dos 130 profissionais entrevistados pelos autores como o principal fator de estímulo à inovação tecnológica nesse setor, seguido pela consciência ambiental da empresa, com $45 \%$, e pela pressão do mercado, com $25 \%$. Apenas $23 \%$ citaram a REP como principal fator indutor. Por sua vez, Sluisveld e Worrell (2013) identificaram 131 modificações em embalagens realizadas na Holanda entre 2005 e 2010 , conforme a tabela a seguir:

\section{Tabela 1. Principais modificações observadas nas embalagens na Holanda}

\begin{tabular}{|c|c|c|c|}
\hline Categoria & (\# ref) Conceito & $\begin{array}{l}\text { Frequência } \\
\text { Aplicação } \\
\text { (\%) }\end{array}$ & $\begin{array}{l}\text { Potencial de } \\
\text { redução de } \\
\text { recursos (\%) }\end{array}$ \\
\hline \multirow{7}{*}{$\begin{array}{l}\text { Eficiência } \\
\text { de material } \\
\text { (redução de } \\
\text { recursos) }\end{array}$} & $\begin{array}{l}\text { (1) Eliminar excesso de } \\
\text { embalagens }\end{array}$ & 9 & 58 \\
\hline & (2) Extensão dos recursos & 1 & - \\
\hline & $\begin{array}{l}\text { (3) Reduzir espaços } \\
\text { vazios/enchimentos }\end{array}$ & 11 & 44 \\
\hline & $\begin{array}{l}\text { (4) Embalagem tamanho } \\
\text { família }\end{array}$ & 3 & 29 \\
\hline & $\begin{array}{l}\text { (5) Redução do peso/ } \\
\text { espessura }\end{array}$ & 31 & 24 \\
\hline & $\begin{array}{l}\text { (6) Escolha de um } \\
\text { material mais leve }\end{array}$ & 2 & 59 \\
\hline & (7) Produtos concentrados & 3 & - \\
\hline \multirow{8}{*}{$\begin{array}{l}\text { Eficiência } \\
\text { energética } \\
\text { (reúso e } \\
\text { reciclagem) }\end{array}$} & (8) Reúso & 2 & - \\
\hline & $\begin{array}{l}\text { (9) Design para } \\
\text { durabilidade }\end{array}$ & 4 & - \\
\hline & (10) Embalagem refil & 1 & 73 \\
\hline & (11) Materiais únicos & 3 & - \\
\hline & $\begin{array}{l}\text { (12) Simplificação da } \\
\text { separação }\end{array}$ & 1 & 37 \\
\hline & (13) Conteúdo reciclado & 9 & 57 \\
\hline & $\begin{array}{l}\text { (14) Substituto } \\
\text { biodegradável }\end{array}$ & 5 & - \\
\hline & (15) Recursos renováveis & 8 & 65 \\
\hline Postergação & $\begin{array}{l}\text { (16) Aumento do tempo } \\
\text { de vida/tempo na } \\
\text { prateleira }\end{array}$ & 1 & - \\
\hline
\end{tabular}

Fonte: Adaptado de Sluisveld e Worrell (2013, p. 138). 
Os autores concluíram que a maioria das iniciativas focou a diminuição do peso das embalagens, devido a sua menor complexidade e por seus ganhos expressivos de competividade na atividade logística. A evolução das garrafas PET ilustra bem essa realidade. De 1985 a 2014, seu peso foi reduzido de 28 para 7,95 gramas, graças a avanços tecnológicos que preservaram a resistência do material (Sidel, 2016). Importante destacar que benefícios ambientais dessa alternativa não podem ser desconsiderados, já que o uso de matéria-prima por unidade produzida também diminui de maneira expressiva. Ainda assim, verifica-se que os avanços para o uso e reciclagem, incluindo reúso, durabilidade, conteúdo reciclado, refil, entre outros, são menos frequentes em relação à inovação para eficiência de material.

Silveira e Chang (2010) afirmam que poucos gestores entendem a REP como uma ferramenta de inovação em prol da sustentabilidade, gerando diferenciação em mercados cada vez mais competitivos. Prevalece uma visão sempre do custo associado ao cumprimento da legislação (Cruz, Simões, \& Marques, 2012). Lifset e Lindqhvist (2008) defendem que um modelo de REP bem-sucedido depende necessariamente de fortes incentivos financeiros para viabilizar a inovação de materiais comprometida com a redução de impactos ambientais.

A experiência europeia indica que os principais desafios parecem estar relacionados a fatores que, de alguma forma, impediram a implantação ótima dos modelos de responsabilização dos produtores, seja pelo fato de não terem fomentado o ecodesign no nível esperado ou mesmo por permitirem que nem todos os fabricantes sejam diretamente responsabilizados pelos seus próprios resíduos. A seguir, discutem-se as principais características do modelo brasileiro de responsabilização dos fabricantes.

\section{A EXPERIÊNCIA BRASILEIRA DE RESPONSABILIDADE ESTENDIDA DO PRODUTOR}

Sancionada pela Lei n. 12.305/2010, a PNRS representa um marco na gestão de resíduos sólidos no país (Gomes et al., 2014; Heber \& Silva, 2014). Entre seus aspectos centrais, destacam-se, no contexto deste trabalho, a responsabilidade compartilhada, a logística reversa, acordos setoriais e o reconhecimento dos catadores de materiais recicláveis na cadeia de reciclagem.

Para Seo e Fingerman (2011), o conceito de responsabilidade compartilhada estabelecido pela PNRS parte do mesmo princípio da REP, incluindo mecanismos de incentivo para que os fabricantes busquem continuamente melhorias em seus produtos e processos, responsabilizando-os pelos impactos ambientais de todo o ciclo de vida do produto. A lei também prevê a implantação da LR reversa por meio dos AS e termos de compromisso, firmados entre o poder público e o setor empresarial (Jesus \& Barbieri, 2013). O AS deve emergir de um processo participativo envolvendo fabricantes, recicladores, varejo e consumidores e cooperativas de catadores, reforçando a dimensão social da PNRS (Batista, 2015).

A integração de todos os atores da cadeia, incluindo as cooperativas de catadores, representa importante passo para a profissionalização da cadeia reversa de reciclagem. Os elevados índices de reciclagem no País para alguns materiais, como alumínio, PET, papelão, são assegurados pelo trabalho de milhares de catadores independentes que garantem a realização da coleta a preços ínfimos, o que viabiliza financeiramente o percurso da embalagem pela cadeia de reciclagem até retornar como matéria-prima ao mercado (Souza, Paula, \& Souza-Pinto, 2012). O elevado grau de informalidade da cadeia de reciclagem contribui para que a atividade enfrente desafios como suprimento incerto de matéria-prima e ociosidade da capacidade produtiva (Santos, Agnelli, \& Manrich, 2004).

Ao ampliar a coleta por meio da disponibilização de postos de entrega voluntária de material reciclável e seu encaminhamento para as cooperativas, somado ao investimento em equipamentos nessas organizações, os tradicionais desafios enfrentados pelas cooperativas de catadores podem ser reduzidos. Eliminação da venda aos intermediários da cadeia, conexão direta entre cooperativas e as grandes recicladoras, aumento da eficiência da separação e consolidação de grandes volumes gerariam, em contrapartida, aumento da renda, diminuição da rotatividade e melhoria das condições de trabalho (Aquino, Castilho, \& Pires, 2009; Demajorovic, Caires, Silva, \& Silva, 2014; Jesus \& Barbieri, 2013; Souza, Paula, \& Souza-Pinto, 2012; Gonçalves-Dias \& Teodosio, 2006).

A construção do AS de embalagens deu-se a partir da iniciativa do poder público em 2012, ao lançar o Edital de Chamamento n 02/2012, convocando os fabricantes, importadores, distribuidores e comerciantes a apresentarem uma proposta formal de modelo de LR para o setor que atendesse aos requisitos estabelecidos pela lei (Yoshida, 2012). 0 Cempre, formado por 22 entidades de classe que representam os fabricantes de embalagens, usuários, distribuidores e comerciantes, apresentou uma proposta para a implementação do sistema de logística reversa para embalagens de produtos não perigosos pós-consumo ao Ministério do Meio Ambiente (MMA) 
em dezembro de 2012. Os avanços esperados foram lentos, pois somente em 2015 o AS de embalagens pós-consumo foi assinado. Os entraves incluíam questões técnicas como modelagem de um novo sistema de LR diante de sistemas específicos já consolidados, como os casos do vidro e do alumínio, e questões culturais como a resistência das empresas a incorporarem os serviços de catadores como fornecedores de serviços na cadeia da LR (Massote, 2014). A expansão dos processos de coleta e a triagem nas cooperativas são alguns dos principais resultados esperados. Destacam-se os 370 municípios que receberam apoio para a instalação de 1.646 PEVs (118 cidades), sendo 1.248 só na Região Metropolitana de São Paulo, e os investimentos em infraestrutura e equipamentos para a expansão da triagem dos materiais recicláveis em 636 cooperativas (339 cidades). As metas de recuperação de recicláveis também devem crescer de $22 \%$, em 2015 , para $45 \%$, em 2031, conforme estabelecido pelo MMA no Edital 02/2012 (Compromisso Empresarial para Reciclagem [Cempre], 2015). A partir da revisão da literatura, é possível formular um modelo teórico, tendo como base o AS, com o objetivo de destacar as relações causais entre as diferentes variáveis e atores que compõem a estratégia de LR para o setor de embalagens.

\section{Figura 1. Modelo teórico preliminar da logística reversa de embalagens no Brasil}

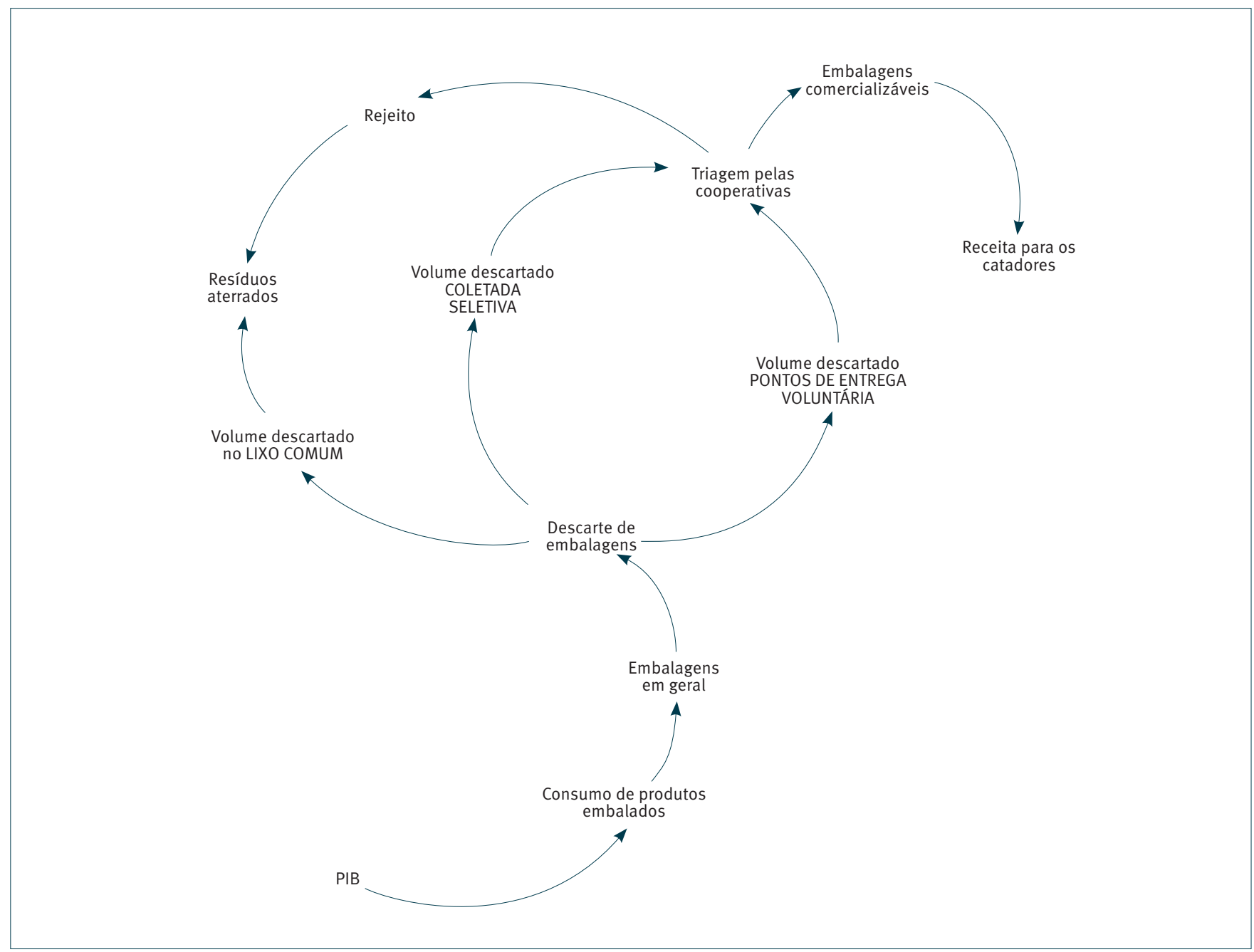

Nesse modelo, temos a consolidação das diversas relações apresentadas ao longo da revisão da literatura e que compõem a estrutura básica da proposta do AS. A interpretação segue uma sequência lógica que tem como início o consumo de produtos embalados sofrendo a influência direta do PIB (Rouw \& Worrell, 2011). 0 descarte de embalagens pode ter diferentes destinações: coleta regular, coleta seletiva e pontos de entrega voluntária. Uma vez descartadas no lixo comum, o destino dessas embalagens será um 
aterro sanitário. Já aquelas descartadas no lixo destinado à coleta seletiva e nos pontos de entrega voluntária serão encaminhadas para as cooperativas de catadores de materiais recicláveis, onde serão triadas por tipo de material. Depois de triadas, uma fração dessas embalagens é, então, comercializada. As demais serão descartadas como rejeito e, na sequência, encaminhadas para os mesmos aterros a que foram destinadas as embalagens descartadas no lixo comum. Aquelas que forem comercializadas geram automaticamente receita para os catadores.

0 resultado esperado é a redução de resíduos enviados a aterros sanitários, ampliando sua vida útil e crescimento da coleta, triagem e comercialização de recicláveis, diminuindo impactos ambientais e gerando benefícios econômicos e sociais. Tais avanços encobrem, no entanto, particularidades do mercado de embalagem e de sua cadeia reversa.

Em primeiro lugar, o acordo trabalha de modo uniforme com todas as embalagens, incluindo alumínio, papel, vidro e plástico, deixando de fora especificidades técnicas de cada material e a realidade do mercado. Os fluxos reversos apresentam diferentes graus de maturidade. Para Jesus e Barbieri (2013), excluindo-se as latas de alumínio, com um índice de 98,3\%, outros tipos de embalagens apresentam resultados bem menos expressivos. Em segundo lugar, a relação peso/volume influencia o potencial de comercialização das embalagens. Uma garrafa PET vazia pesa em média $45 \mathrm{~g}$, sendo necessário juntar 22 garrafas para acumular um quilo de material. Isso faz com que o valor de uma garrafa PET na cidade de São Paulo seja de aproximadamente $\mathrm{R}$ \$ 0,07, considerando o material prensado e lavado. Já uma embalagem de salgadinhos pesa em média 3 g, necessitando 333 embalagens para compor um quilo. Nesse caso, o valor médio de uma embalagem de salgadinho, caso seja comercializada como plástico-filme, é de $\mathrm{R} \$ 0,003$, um valor unitário 20 vezes menor que a da garrafa PET (Massote, 2014). Essa baixa relação peso/ volume das embalagens flexíveis é, para Leite (2009), o principal fator de restrição ao aumento dos índices de reciclagem desses materiais, pois não possibilita uma remuneração adequada dos agentes da cadeia reversa.

Um terceiro fator é a complexidade de alguns tipos de embalagens utilizadas no mercado. A presença de materiais como o alumínio, papel-cartão, tintas, vernizes, entre outros produtos comumente usados nos processos de laminação e impressão de embalagens plásticas a fim de melhorar o desempenho delas, são identificados como contaminantes. Para Forlin e Faria (2002), quanto menor a quantidade de materiais utilizados na mesma embalagem, menos complexo será o processo de reciclagem e consequentemente maior o valor de comercialização desses materiais. Coltro e Duarte (2013) analisaram 509 embalagens plásticas flexíveis do mercado brasileiro utilizadas para acondicionar tanto alimentos quanto produtos não alimentícios e constataram que 39\% das embalagens plásticas flexíveis correspondem a estruturas multicamadas. Essa maior complexidade acaba por reduzir seu valor comercial, reduzindo sua atratividade para catadores triarem e consolidarem esse tipo de material.

Por fim, outra questão importante relativa à viabilidade econômica da reciclagem dessas embalagens é o peso da tributação. A matéria-prima reciclada não recebe qualquer tipo de incentivo tributário, o que onera demasiadamente o processo de reciclagem e diminui sua competitividade perante as matériasprimas virgens. Para Nepomuceno (2006), a cobrança de impostos deveria ocorrer somente sobre os produtos acabados produzidos a partir da matéria-prima reciclada, porém não sobre a venda desta, uma vez que foram geradas por meio da recuperação de matériasprimas previamente usadas na indústria de transformação e, consequentemente, já tributadas.

\section{METODOLOGIA}

Por se tratar de fenômeno bastante recente na literatura e pouco pesquisado no cenário acadêmico, optou-se por uma abordagem qualitativa de caráter exploratório e interpretativo para estudar o impacto do AS na cadeia reversa de embalagens.

A coleta de dados teve como base os documentos e reuniões da coalização liderada pelo Cempre para a construção do AS e entrevistas por meio de um roteiro semiestruturado. A seleção de entrevistados foi intencional, de modo a representar os diferentes atores envolvidos. No entanto, alguns entrevistados foram incluídos a partir da técnica snowball ou bola de neve a partir da indicação do primeiro grupo de entrevistados escolhidos. Para Bayley (1994), uma reduzida amostra não probabilística, ainda que não permita análise estatística, é bastante adequada para abordagens exploratórias que poderão ser seguidas por estudos quantitativos. Complementa-se que o critério teórico de saturação ou redundância, definido por Glaser e Strauss (1967), revela que a amostra escolhida foi suficiente para garantir uma ampla análise do objeto da pesquisa. As questões abordaram os seguintes conteúdos: importância do AS e seus benefícios e limites, desenvolvimento de embalagens, barreiras para a reciclagem, incorporação das cooperativas no processo e incentivos financeiros. Conforme estabelecido com os entrevistados, garantiu-se seu anonimato, usando-se para este trabalho um sistema de codificação alfanumérica cujas três primeiras letras representam a categoria do entrevistado e um 
número que representa a ordem do entrevistado dentro de cada categoria. Os 16 entrevistados incluíram: gestor de associação de classe - CLA1; reciclador - REC1, REC2; fabricante de embalagem - FAB1, FAB2; especialista em tributação ambiental - TRl1; gestor público - GES1, GES2, GES3; cooperativas - COP1, $\mathrm{COP}_{2}, \mathrm{COP}_{3}$; designers de embalagens - DES1, DES2; e gestor de sustentabilidade - SUS1, SUS2. As entrevistas foram gravadas e transcritas, e foi omitida qualquer informação que permitisse identificar indivíduos ou organizações. Para a análise dos dados, adotou-se a técnica de análise de conteúdo, que tem por finalidade básica buscar o significado de materiais textuais como artigos, entrevistas ou livros (Appolinário, 2012). Um passo importante dessa técnica é a redução do material original. Esse processo de codificação, no qual as características relevantes do conteúdo de uma mensagem são transformadas em unidades que possibilitem análises mais precisas, é formado pela definição do "universo", "unidades de análise" e "categorias de análise" (Sampieri, Collado, \& Lucio, 2012).

\section{Quadro 1. Categorias analíticas}

\begin{tabular}{l|l}
\hline Categorias de análise & Referências \\
\hline $\begin{array}{l}\text { Aspectos inovadores e } \\
\text { benefícios da PNRS e AS }\end{array}$ & $\begin{array}{l}\text { Gomes e outros (2014); Heber e Silva } \\
(2014)\end{array}$ \\
\hline $\begin{array}{l}\text { Custo vs. impacto } \\
\text { ambiental }\end{array}$ & $\begin{array}{l}\text { Lifset e Lindhqvist (2008); Cruz et al. } \\
(2012)\end{array}$ \\
\hline $\begin{array}{l}\text { Desafios para } \\
\text { implantação da LR } \\
\text { (desafios logísticos, } \\
\begin{array}{l}\text { desafios técnicos, } \\
\text { desenvolvimento de } \\
\text { materiais) }\end{array}\end{array}$ & $\begin{array}{l}\text { Røine e Lee (2006); Leite, (2009); } \\
\text { Forlin e Faria (2002) }\end{array}$ \\
\hline $\begin{array}{l}\text { Inserção de cooperativas } \\
\text { Acordo coletivo } \\
\text { individualizadas }\end{array}$ & $\begin{array}{l}\text { Jesus e Barbieri (2013); Demajorovic } \\
\text { (2014) }\end{array}$ \\
\hline $\begin{array}{l}\text { Incentivos econômicos } \\
\text { Atasu, Wassenhove e Sarvary (2009); } \\
\text { Brouillat e Oltra (2012); Kalimo et al. } \\
\text { (2012) }\end{array}$ \\
\hline \begin{tabular}{l} 
Lifset e Lindhqvist (2008) \\
\hline
\end{tabular}
\end{tabular}

Após a codificação, os fragmentos foram organizados por categoria procurando identificar elementos concordantes e contraditórios nas falas dos respondentes e triangulando com os documentos analisados.

\section{RESULTADOS DA PESQUISA}

A primeira categoria analítica centrou-se no caráter inovador e benefícios da PNRS e do AS. Para os entrevistados, a criação do conceito de responsabilidade compartilhada, embora ainda não incutido efetivamente na rotina empresarial, é essencial para que haja uma transformação na forma de desenvolver e fabricar novos produtos (TRI-1; GES-2). Há um consenso de que a indústria será obrigada a priorizar investimentos na área de inovação, buscando reduzir impactos socioambientais de seus produtos e embalagens. A lei já cita recomendações nesse sentido no artigo 32, e algumas empresas que hoje embalam seus produtos com materiais não recicláveis já deram os primeiros passos para o desenvolvimento de alternativas (TRI-1; COP-1; CLA-1; SUS 1). COP 3 relata ter sido procurada recentemente por empresas a fim de entender a possibilidade de comercialização ou não das embalagens produzidas por elas, o que reforçaria o caráter indutor da legislação para a inovação de materiais. Outro aspecto importante citado por cooperativas e gestores empresariais foi a perspectiva de aumento da coleta com ampliação dos pontos de entrega voluntária e ampliação das metas de reciclagem presentes no AS (CLA 1; GES 2; COP 2).

Apesar dos avanços identificados, os desafios do processo, que compõem a segunda categoria, predominam na visão dos entrevistados. Se a interação entre os atores é valorizada, a divisão de responsabilidade mostrou-se como um grande desafio para a implantação do AS. Para seis dos entrevistados, não há definições satisfatórias sobre os papéis de cada um dos envolvidos no cumprimento dos requisitos mínimos exigidos pela lei e sobre a divisão dos custos decorrentes da implantação da logística reversa. A falta de definição contribui para a morosidade das mudanças no processo de projetar e fabricar produtos nas empresas. (GES-2; TRI-1).

Enquanto as embalagens mais complexas continuarem a ser muito mais competitivas em termos de logística e proteção do produto, continuarão a pautar o desenvolvimento de materiais, ainda que eliminem a possibilidade de reaproveitamento (DES-2).

$\mathrm{Na}$ visão dos recicladores, esse processo só poderia ser revertido se o próprio reciclador conseguir se preparar e se estruturar para manusear produtos mais complexos. Para tanto, é necessário o trabalho conjunto com os fornecedores de embalagens, já que estes conhecem bem tecnicamente as funções delas e podem auxiliar a indústria que as utiliza a efetuar mudanças que as tornem mais sustentáveis (REC1; CLA-1).

Ao tratar de investimentos necessários para melhoria do desempenho ambiental dos produtos, porém, a questão dos custos emerge como principal entrave. Para gestores empresariais, 
cooperativas e tributaristas, modificações em produtos e embalagens serão implantadas somente se não afetarem a competividade, ou seja, apenas se os custos forem reduzidos ou mantidos no atual patamar (SUS-1; CLA-1; TRI-1; COP-2; REC2).

Outros entraves para a implantação da logística reversa de embalagens incluem: dificuldades logísticas; falta de aplicações e demanda pelo produto reciclado; dificuldades técnicas de reciclagem de alguns materiais; e dificuldade de garantia de fornecimento. A dimensão geográfica do País, que torna a coleta das embalagens e também o seu encaminhamento para o destino final correto bastante complexo, além de questões de segurança, foi destacada como entrave logístico (SUS-1; SUS-2; DES-1; TRI-1). Já a falta de demanda e busca por aplicações para o produto reciclado foi enfatizada pelo conjunto de cooperativas entrevistadas, especialmente no que se refere à comercialização de embalagens multicamadas. Nas palavras de $\mathrm{COP}_{3}$, “muitas embalagens entram na esteira como recicláveis, mas saem dela como rejeito".

Para os recicladores de produtos plásticos, "a culpa é da própria indústria geradora que não está aberta a reutilização do material reciclado proveniente do seu próprio resíduo" (REC 2). Um dos exemplos está relacionado à questão da cor do produto final. Produtos reciclados naturalmente tendem a apresentar colorações escuras como preto, verde-escuro e cinza-escuro. Para obter tons mais claros ou puros como branco, amarelo e vermelho, faz-se necessário o uso de aditivos químicos como os pigmentos, mas isso encarece o produto final, muitas vezes inviabilizando sua aplicação. Uma alternativa seria os fabricantes mudarem o apelo dos produtos e embalagens, dando abertura para a utilização dos materiais reciclados, respeitando suas propriedades visuais e mecânicas sempre que possível (REC 3).

Já a dificuldade de garantia de suprimento na quantidade necessária para viabilizar projetos de produtos fabricados a partir desse insumo foi apontada como uma razão para que fabricantes abandonem projetos com potencial para incorporação de materiais reciclados na fabricação de novos produtos.

A diferença entre o discurso e a prática de usuários de embalagens foi reforçada como mais um empecilho para a expansão da reciclagem, considerando o padrão de desenvolvimento de materiais.

A maionese que hoje é embalada em um sachê flexível de diferentes materiais laminados (PET + PE + alumínio) antes era embalada em potes rígidos de PP. A nova embalagem flexível, depois de descartada, não pode ser usada nem mesmo na fabricação de telhas porque a lavagem deste material é complexa, já que estas colam, grudam, dobram e dificultam o processo. $\mathrm{O}$ valor agregado dos potes rígidos de PP era competitivo no mercado, uma vez que se trata de material rígido e mais fácil de se lavar do que as embalagens flexíveis (REC-1).

O entrevistado cita, ainda, que todas as embalagens laminadas compostas por alumínio não podem ser recicladas junto com o plástico, a menos que passem por uma etapa de micronização, o que encarece e torna mais complexa a reciclagem.

Muitos dos entraves apresentados acima afetam diretamente o processo de inserção das cooperativas de catadores na LR. Embalagens complexas dificultam a separação dos materiais e restringem as possibilidades de comercialização de parcela dos materiais recebidos por elas. Ao questionar COP-1 sobre esse ponto, o maior entrave levantado foi a necessidade de pagamento antecipado de todos os custos envolvidos na logística reversa, coletor e motoristas, sem a garantia de que esses materiais serão posteriormente comercializados.

Ao aprofundar a visão dos entrevistados sobre a situação atual das cooperativas, problemas históricos associados à governança e iniciativas de verticalização foram reforçados, tais como melhorias na gestão, melhor formalização das atividades das cooperativas e treinamento e capacitação dos cooperados. Para TRI-1, "caso não haja estas mudanças, não adiantará em nada aumentar a quantidade de materiais entregues às cooperativas para que sejam triados".

Com relação à categoria que trata da efetividade de acordos coletivos ou propostas individualizadas, gestores empresariais, especialista tributário e cooperativas justificam a opção pelo primeiro pela simplificação do processo de cumprimento da lei e aparente redução do custo de atendimento dessa mesma lei (GES-2; SUS-1; COP-2; TRI-1).

A proposta coletiva foi justificada também pela falta de incentivos fiscais e tributários que integram a última categoria analítica. Diversos entrevistados citaram a criação de incentivos econômicos como a principal medida a ser tomada pelo governo, de modo a desonerar a cadeia de reciclagem atual e incentivar o uso do material reciclado sempre que possível (TRI-1; SUS-1; CLA-1). Para um gestor de associação de classe, os incentivos fiscais precisam ser disponibilizados, "já que todo o material que passa pela reciclagem já pagou impostos antes. Quando esse material tiver que ser tratado para posteriormente voltar para o mercado, terá que pagar todos os impostos novamente" (CLA-1). Já um gestor em sustentabilidade cita o incentivo de crédito presumido de IPI na aquisição de material reciclado que já foi aprovado no Brasil, mas que ainda é muito mal divulgado e estruturado, o que acaba inviabilizando sua utilização (SUS-1).

Para os materiais difíceis de reciclar como as embalagens multicamadas, os incentivos são ainda mais importantes para viabilizar o reaproveitamento e comercialização no mercado de 
reciclagem. Para recicladores, a saída seria transferir qualquer excedente de custo de reciclagem para o preço final da resina, porém os preços são regulados pelo mercado, e não existe espaço para grandes mudanças. A alternativa seria conseguir algum subsídio tributário ou fiscal que compensasse o excedente de custo (REC-1).

Ainda assim, a questão tributária não pode explicar totalmente a opção do AS. Foi destacado por um gestor público que o AS vem sendo apresentado como uma iniciativa do setor privado. No entanto, ele se beneficia de ações do município, como "os investimentos já feitos em cooperativas para sua implantação e manutenção da operação, já incorporados no orçamento municipal” (GES-3). Nesse sentido, o acordo pega uma carona na estrutura já em operação para ampliar seus resultados a um custo bastante reduzido para cada um de seus integrantes.

Por fim, gestores públicos, privados e cooperativas citaram também o importante papel dos consumidores em impulsionar a adoção de embalagens mais sustentáveis por parte dos fabricantes e o cumprimento das metas de coleta e reciclagem definidas pelo AS, embora TRI-1 acredite que o preço ainda seja o "principal fator influenciador da compra e não o impacto ambiental do produto". Já para um gestor público, o desafio do AS para atingir suas metas será o mesmo que os já enfrentados pelos programas municipais de coleta seletiva: "a baixa adesão da população aos programas de reciclagem” (GES-2).

\section{DISCUSSÃO DOS RESULTADOS}

As informações obtidas por meio das entrevistas realizadas com especialistas e entidades diretamente relacionadas com a PNRS e 0 AS apresentam pontos de vista bastante convergentes com relação aos aspectos inovadores e entraves para a sua implantação. As entrevistas permitem também que seja traçado um interessante paralelo entre a realidade percebida pelos diversos atores aqui no Brasil após a aprovação da PNRS e os resultados encontrados em outros países, sobretudo os europeus, após a implantação de suas políticas públicas ligadas a gestão de resíduos.

Como primeiro resultado, destaca-se que, embora a PNRS tenha como princípio a responsabilização da cadeia por todo o ciclo de vida do produto, o AS privilegia a coleta, e não a reciclagem. Sem diretrizes claras para um processo de engajamento da cadeia para diminuição dos impactos em todas as fases de desenvolvimento, produção e comercialização de produtos, o principal desdobramento poderá ser um aumento expressivo do volume coletado de embalagens e de material triado nas cooperativas. Somado aos prometidos investimentos em equipamentos nas cooperativas, a verticalização e venda direta para recicladores poderia se efetivar, impactando positivamente a renda e reduzindo sua vulnerabilidade, conforme apontado também nos estudos de Souza, Paula e Souza-Pinto (2012), Jesus e Barbieri (2013), e Demajorovic et al. (2014).

No entanto, no que se refere à busca por inovação nos produtos, as informações levantadas reforçam os resultados, apresentados por Brouillat e Oltra (2012), de que somente metas e responsabilização individualizada, além de taxas proporcionais à reciclabilidade do material, produzirão efeitos significativos nos índices de reciclagem, estimulando o investimento em P\&D para materiais de menor impacto ambiental. O processo de inovação das embalagens por meio de estruturas multicamadas prioriza redução de custo e vantagens logísticas em detrimento da reciclibilidade, corroborando os estudos de Røine e Lee (2006), Sluisveld e Worrel (2013), e Coltro e Duarte (2013).

Por ora, o principal efeito da nova política será a divisão dos custos da logística reversa dos resíduos recicláveis entre os atores envolvidos, mas sem que estejam previstos incentivos para iniciativas de ecodesign visando melhorias nas embalagens e produtos. Ressalta-se que a contribuição para cobrir os custos está atrelada à quantidade de embalagens/produtos colocados no mercado, independentemente das características do material empregado. Conforme um representante dos fabricantes de embalagem entrevistado, os fabricantes contribuem apenas com as chamadas despesas de governança como assessoria jurídica e técnica, eventos e viagens, enquanto os recursos para cooperativas são rateados entre todas as empresas de bens de consumo integrantes do acordo. Nesse sentido, não surpreende a valorização de grande parte dos entrevistados da alternativa coletiva, destacando-se o compartilhamento da responsabilidade entre vários fabricantes e a divisão dos custos do projeto, barateando o custo total. Destaca-se a informação de um gestor de associação de classe entrevistado que pontuou que o custo anual para adesão ao acordo coletivo poderá ser "em torno de $\mathrm{R} \$ 1.000,00$ para algumas empresas pertencentes ao setor de embalagens plásticas".

Sem impactos significativos na estrutura de custos das empresas usuárias de embalagem e sem metas claras de reciclabilidade defendidas por Thorpe et al. (2004), o AS tenderá a beneficiar somente as embalagens já com cadeias mais estruturadas, como alumínio, PET e papelão. Problemas estruturais da cadeia de reciclagem, como materiais com níveis diferentes de atratividade (Jesus \& Barbieiri, 2013), dificuldades enfrentadas pela indústria em garantir fornecimento constante e com qualidade de materiais recicláveis para aplicação em seus processos produtivos (Rodrigues et al., 2005), ficarão dependentes de eventual interesse dos setores de desenvolvimento de materiais e recicladores. 
Outro ponto destacado nas entrevistas foi o entendimento de que somente quando houver oportunidades de redução de custo no produto ou na embalagem é que projetos de melhorias serão desenvolvidos. Esta é a expectativa tanto dos próprios fabricantes de produtos embalados quanto dos outros atores envolvidos nessa cadeia. Isso explica por que a questão dos incentivos econômicos foi um tópico recorrente. Embora a PNRS apresente, em seu terceiro capítulo, artigo $8^{\circ}$, inciso IX, os incentivos fiscais, financeiros e creditícios como instrumentos para sua implantação, a falta de clareza apontada pelos entrevistados corrobora os estudos de Silva Filho e Soler (2012).

O discurso dos fabricantes e recicladores coincide com os argumentos de Atasu e Wassenhove (2012) de que a legislação deve ser cautelosa em não onerar demais os produtores de modo a reduzir a competitividade. Ainda que os impactos financeiros do AS sejam, na realidade brasileira, irrisórios, conforme discutido, a questão da bitributação dos produtos recicláveis não pode ser relegada a um segundo plano. Os entrevistados acreditam que os incentivos mais eficazes são cobranças que incidam sobre a comercialização de materiais reciclados e produtos fabricados a partir desses materiais, como ICMS e IPI. Reduções nessas alíquotas incentivam os fabricantes a utilizarem mais materiais reciclados, aumentando a demanda por esses materiais e consequentemente aumentando a receita das cooperativas.

A partir da discussão apresentada, é possível propor um modelo conceitual que represente o AS em sua fase de implementação.

\section{Figura 2. Modelo teórico atualizado após a realização das entrevistas}

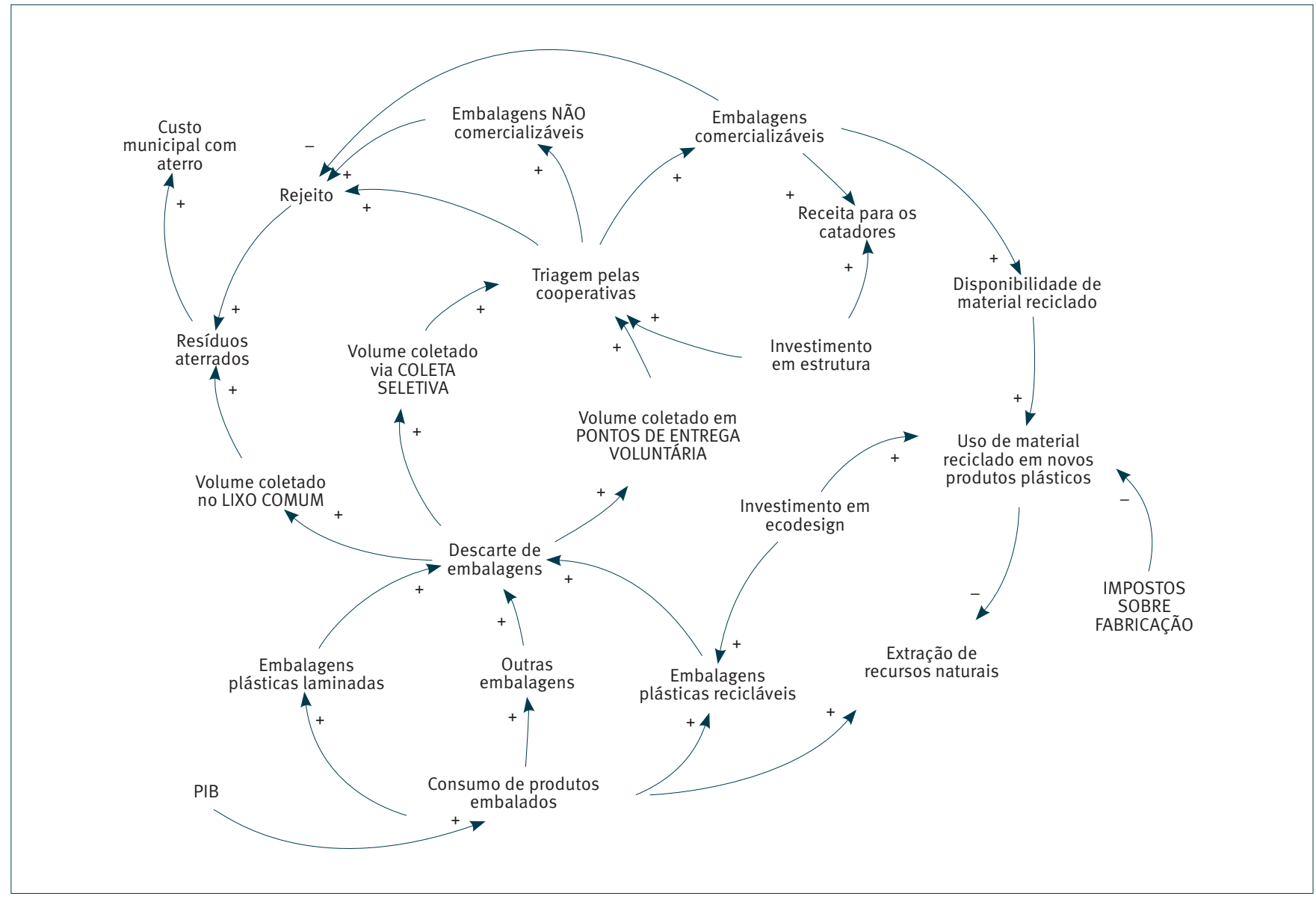

Esse modelo atualizado propõe novas variáveis e relações causais em relação ao anterior. A interpretação desse modelo também tem início na premissa de que o consumo de produtos embalados acompanha a variação do PIB. Esse aumento do consumo de produtos embalados tem como efeito a elevação do uso de todos os tipos de embalagem, incluindo agora multicamadas e plásticas laminadas. 
As embalagens pertencentes aos três grupos utilizados neste trabalho são descartadas após o consumo. O AS garante maior volume de material processado nas cooperativas e, somado ao investimento em infraestrutura nessas organizações, cria um ciclo virtuoso de crescimento de embalagens comercializáveis e geração de renda. No entanto, em função das características de desenvolvimento das embalagens aqui discutidas, o novo modelo traz uma nova variável. Aquelas que não são diretamente comercializadas deixam de ser classificadas apenas como rejeito e passam a ganhar outra subdivisão, denominada "embalagens não comercializáveis", apenas para identificar que existe uma oportunidade de reaproveitamento dessas embalagens antes que sejam descartadas como rejeito e encaminhadas aos aterros, como no caso de algumas embalagens multicamadas. Os resíduos encaminhados aos aterros dão origem a uma nova variável no modelo, intitulada "custo municipal com aterro", valor que cresce à mesma velocidade a que cresce o volume de resíduos encaminhados para esse fim.

Nesse cenário, infere-se que os resultados positivos esperados pelo AS precisam ser relativizados em função do padrão atual do desenvolvimento de embalagens. Parte dos resíduos coletados e entregues às cooperativas voltará a alimentar os aterros, uma vez que não apresenta potencial de comercialização, embora seja comercializada como materiais recicláveis. 0 problema também é agravado pela total ausência de mecanismos efetivos que assegurem os fluxos representados no lado direito da figura. A ausência de metas individualizadas, custos irrisórios para as empresas cumprirem a legislação e ausência de tributação específica que estimule o consumo de material reciclado tornam o objetivo de promover o ecodesign elemento bastante distante e limitante do acordo proposto.

\section{CONCLUSÕES}

A PNRS representa um importante marco para a gestão dos resíduos no Brasil e afetará diferentes setores de maneiras e intensidades distintas. Apesar de seu caráter inovador e de avançar sobre alguns desafios, como o de incluir as cooperativas de catadores de materiais recicláveis nesse fluxo, não existem elementos que apontem para sua contribuição para o processo de desenvolvimento de produtos e embalagens mais sustentáveis de maneira efetiva. Verifica-se que o AS de embalagens privilegiou os aspectos econômicos relacionados à divisão dos custos de LR das embalagens em geral e pouco contempla ações concretas para o melhor reaproveitamento dessas embalagens a fim de evitar que sejam encaminhadas aos aterros.
Como resultado esperado e respondendo à primeira questão de pesquisa, o AS tende a impactar positivamente a cadeia de reciclagem, principalmente considerando as cadeias mais estruturadas, como papel, papelão, vidro, plásticos rígidos e alumínio. Para esses materiais, espera-se uma ampliação da coleta, com desvio de parcelas crescentes de resíduos de aterros sanitários e resultados positivos para cooperativas de catadores. Nesse caso, se os compromissos de melhoria de sua infraestrutura também forem assegurados, a consolidação de grandes volumes resíduos e da venda direta para os grandes recicladores, e não apenas intermediários, deverá se ampliar.

No entanto, o AS encobre diversas facetas pouco discutidas até o momento na literatura. Primeiro, a implementação do acordo possibilita que fabricantes e usuários de embalagem sejam freeriders de estruturas já financiadas pelas autoridades municipais, sem uma contrapartida a esse investimento já realizado. Os recursos que são investidos em cooperativas por parte da prefeitura, como disponibilização do galpão e pagamentos de despesas de operação, continuarão a ser responsabilidade do setor público. Enquanto isso, a questão da remuneração das atividades da cooperativa, uma importante bandeira do movimento nacional de catadores, foi desconsiderada pelo AS.

Em segundo lugar, e principal questão desta pesquisa, fabricantes integrantes do acordo cumprirão os requisitos legais estabelecidos pela PNRS a um custo bastante reduzido. Além do valor pouco expressivo, os fabricantes e usuários de embalagens não terão qualquer obrigação individual de encontrar uma solução para a reciclagem das embalagens que hoje colocam no mercado. A uniformidade de tratamento de materiais encobre a realidade da capacidade de absorção da cadeia de reciclagem brasileira. Uma parcela importante dos materiais coletados, embora veiculado muitas vezes na mídia como materiais recicláveis, assume para este trabalho a categoria de não comercializável. Tal lacuna, além de não influenciar o redirecionamento do desenvolvimento de embalagens, poderá inclusive alimentar a forma tradicional de inovação de materiais, uma vez que a questão de destinação deixa de ser um fator limitante para os integrantes do acordo. Além disso, a redução esperada do custo municipal, com o maior desvio de resíduos do aterro sanitário, deverá ser relativizada pelo aumento também proporcional de embalagens não comercializáveis triadas nas cooperativas e que deverão ser encaminhadas para sua disposição, atividade custeada até o momento inteiramente por parte do setor público, como parte de suas atribuições no programa de coleta seletiva em parceira com as cooperativas.

Assim, esta pesquisa reforça a necessidade de ampliação de estudos fortalecendo os argumentos críticos do processo 
de implantação da PNRS e AS. O AS e a ausência de metas individuais propiciam uma alternativa para que as empresas cumpram a legislação a custos bastante reduzidos. Ao tratar de embalagens de características diferentes de modo uniforme, somado ao paradigma de desenvolvimento de embalagens que privilegia a competitividade em detrimento da reciclabilidade, comprometem-se os resultados prometidos pelo AS, principalmente no que se refere ao desenvolvimento de produtos e embalagens mais sustentáveis. Assim, estudos futuros devem focar questões como os incentivos financeiros e tributários como um elemento complementar essencial para o sucesso da PNRS.

Primeiro, porque reduziria o problema da bitributação no sistema atual, já que os materiais recicláveis não têm qualquer tipo de isenção fiscal. Impostos reduzidos incentivam toda a cadeia, começando pelos catadores, passando pelos recicladores, depois pelos fabricantes com potencial para utilização do material reciclado, indo até os consumidores.

Segundo, isenções maiores para embalagens que representem menos custo ambiental para seu reaproveitamento podem incentivar maiores investimentos em materiais menos complexos para seu reaproveitamento ou mesmo desenvolvimento de tecnologias para reaproveitamento de materiais hoje não comercializáveis, como as estruturas multicamadas.

Ressalta-se que essa alternativa é extremante complexa na realidade brasileira, diante da resistência do setor empresarial a qualquer medida que promova a internalização de custos ambientais. A própria aprovação da PNRS tardou 20 anos em função do conhecido lobby do setor empresarial em aceitar a responsabilização pós-consumo. Na ausência do aprimoramento da legislação, caberia aos consumidores optar por produtos mais sustentáveis e fazer com que suas escolhas forcem os fabricantes a repensarem seus produtos, a fim de recuperar a participação de mercado eventualmente perdida para os fabricantes mais sustentáveis. No entanto, esse cenário parece pouco provável, na medida em que os limites do AS necessitam ser muito mais aprofundados e principalmente comunicados de modo que a PNRS possa efetivamente cumprir seus objetivos ambientais e influenciar a pesquisa em embalagens para além das necessidades de competitividade.

\section{REFERÊNCIAS}

Aquino, I. F., Castilho Jr. A. B., \& Pires, T. S. de L. (2009). A organização em rede dos catadores de materiais recicláveis na cadeia produtiva reversa de pós-consumo da região de grande Florianópolis: Uma alternativa de agregação de valor. Gestão \& Produção, 16(1), 15-24. doi:10.1590/S0104-530X2009000100003
Appolinário, F. (2012). Metodologia da ciência: Filosofia e prática da pesquisa ( 2 a ed.). São Paulo, SP: Cengage Learning.

Atasu, A., \& Wassenhove, L. (2012). Operations perspective on product take-back legislation for e-waste: Theory, practice and research needs. Production and Operations Management, 21(3), 407-422. doi:10.1111/j.1937-5956.2011.01291.x

Atasu, A., Wassenhove, L., \& Sarvary, M. (2009). Efficient take-back legislation. Production and Operations Management, 8(3), 243-258. doi:10.1111/j.1937-5956.2009.01004.x

Batista, V. F. (2015). As políticas públicas de coleta seletiva no município do Rio de Janeiro: Onde e como estão as cooperativas de catadores de materiais recicláveis? RAP-Revista de Administração Pública, 49(1), 141-164. doi:10.1590/0034-76121603

Bayley, K. D. (1994). Methods of social research (4. ed.). New York, USA: The Free Press.

Brouillat, E., \& Oltra, V. (2012). Extended producer responsibility instruments and innovation in ecodesign: An exploration through a simulation model. Ecological Economics, 83, 236-245. doi:10.1016/j. ecolecon.2012.07.007

Cahill, R., Grimes, S., \& Wilson, D. (2010). Extended producer responsibility for packaging wastes and WEEE: A comparison of implementation and the role of local authorities across Europe. Waste Management and Research, 29(5), 455-479. doi:10.1177/0734242X10379455

Compromisso Empresarial para Reciclagem. (2015). Cempre review 2015: Um panorama reciclagem no Brasil. Recuperado de http:// cempre.org.br/artigo-publicacao/artigos

Coltro, L., \& Duarte, L. (2013). Reciclagem de embalagens plásticas flexíveis: Contribuição da identificação correta. Revista Polímeros, 23(1), 128-134. doi:10.1590/S0104-14282013005000008

Cruz, N., Simões, P., \& Marques, R. (2012). Economic cost recovery in the recycling of packaging waste: The case of Portugal. Journal of Cleaner Production, 37, 8-18. doi:10.1016/j.jclepro.2012.05.043

Cruz, N. F., Ferreira, S., Cabral, M., Simão, P., \& Marques, R. C. (2014). Packaging waste recycling in Europe: Is the industry paying for it? Waste Management, 34(2), 298-308. doi:10.1016/j. wasman.2013.10.035

Demajorovic. J., Caires, E. F., Silva, L. N., \& Silva, M. J. C. (2014) Integrando empresas e cooperativas de catadores em fluxos reversos de resíduos sólidos pós-consumo: O caso Vira-Lata. Cadernos EBAPE. $B R, 12$ (dição especial), 513-532. doi:10.1590/1679-39519020

Demajorovic, J., Zuñiga, M. K. H. M., Boueres, J. A., Silva, A. G., \& Sotano, A. L. (2012). Logística reversa: Como as empresas comunicam o descarte de celulares. RAE-Revista de Administração de Empresas, 52(2), 165-178. doi:10.1590/So034-75902012000200004

Forlin, F. J., \& Faria, J. A. F. (2002). Considerações sobre a reciclagem de embalagens plásticas. Revista Polímeros, 12(1), 1-10. doi:10.1590/ S0104-14282002000100006

Glaser, B. G., \& Strauss, A. L. (1967). The discovery of grounded theory: Strategies for qualitative research. Chicago, USA: Aldine Publishing Company.

Gomes, M. H. S. C., Oliveira, E. C., Brescian, L., \& Pereira, R. S. (2014). Política nacional de resíduos sólidos: Perspectivas de cumprimento da Lei 12.305/2010 nos municípios brasileiros, municípios paulistas e municípios da região do ABC. Revista de Administração da UFSM, 7 , edição especial, 93-110. doi:10.5902/1983465913026 
Gonçalves-Dias, S. L. F, \& Teodósio, A. S. S. (2006). Estrutura da cadeia reversa: "Caminhos" e "descaminhos" da embalagem PET. Produção, 16(3), 429-441. doi:10.1590/S0103-65132006000300006

Heber, F., \& Silva, E. M. (2014). Institucionalização da política nacional de resíduos sólidos: Dilemas e constrangimentos na região metropolitana de Aracaju (SE). RAP-Revista de Administração Pública, 48(4), 913-937. doi:10.1590/0034-76121537

Jacobi, P. R., \& Besen, G. R. (2011). Gestão de resíduos sólidos em São Paulo: Desafios da sustentabilidade. Revista Estudos Avançados, 25(71), 135-158. doi:10.1590/S0103-40142011000100010

Jesus, F. S. M., \& Barbieri, J. C. (2013). Atuação de cooperativas de catadores de materiais recicláveis na logística reversa empresarial por meio de comercialização direta. Revista de Gestão Social e Ambiental, 7(3), 20-36. doi:10.24857/rgsa.v7i3.816

Kalimo, H., Lifset, R., Rossem, C. van, \& Mayers, K. (2012). Greening the economy through design incentives: Allocating extended producer responsibility. European Energy and Environmental Law Review, 21(6), 274-305.

Lambert, J. (2012) The influence of extended producer responsibility on ecodesign practices: Insights from six producer case studies in the european ICT sector (Dissertação de mestrado, University of Utrecht and the University of Leipzig).

Leite, P. R. (2009). Logística reversa: Meio ambiente e competitividade. São Paulo, SP: Pearson Prentice Hall.

Lifset, R., \& Lindhqvist, T. (2008). Producer responsibility at a turning point? Journal of Industrial Ecology, 12(2), 144-147. doi:10.1111/ j.1530-9290.2008.00028.x

Massote, B. (2014). Os limites da política nacional de resíduos sólidos no setor de embalagens plásticas flexíveis no Brasil: Uma abordagem de dinâmica de sistemas (Dissertação de mestrado em administração, Centro Universitário da FEI, São Paulo).

Nepomuceno, N., Sobrinho. (2006). A tributação sobre o setor de reciclagem de resíduos sólidos e a incapacidade contributiva das associações e cooperativas de catadores: Uma sociedade em busca da sustentabilidade (Dissertação em administração, Universidade de Brasília, Brasília).

Organization for Economic Co-operation and Developmen. (2005). Analytical framewok for evaluating the costs and benefits of extended produced responsibility programmes. OECD Environment Programme. Recuperado de http://www.oecd.org/env/waste

Política Nacional de Resíduos Sólidos. (2010). Lei n. 12.305, de 2 de agosto de 2010. Recuperado de http://www.planalto.gov.br/ ccivil_03/_at02007-2010/2010/lei/l12305.htm

Pro-Europe. (2010). Producer responsibility in action. Recuperado de http://pro-e.org/files/PRO-EUROPE_Producer-Responsibility-inAction_web-version_final_150811.pdf

Rodrigues, I., Righetti, C. C. B., Facó, J. F. B., Sakumaroto, C. Y., \& Barbieri, J. C. (2005). Estratégias de gestão ambiental nas empresas: Um estudo de caso sobre o papel reciclado. In: XXIX EnANPAD 2005, São Paulo.

Rogers, D. S., \& Tibben-Lemke, R. S. (1998). Going backwards: Reverse logistics trends and practices. Reno, USA: Reverse Logistics Executive Council.
Røine, K., \& Lee, C. Y. (2006). With a little help from EPR? Technological change and innovation in the Norwegian plastic packaging and electronics sectors. Journal of Industrial Ecology, 10(1-2), 217-237. doi:10.1162/108819806775545448

Rouw, M., \& Worrell, E. (2011). Evaluating the impacts of packaging policy in The Netherlands. Resources, Conservation and Recycling, 55(4), 483-492. doi:10.1016/j.resconrec.2010.12.013

Rubio, S., Chamorro, A., \& Miranda, F. J. (2008). Characteristics of the research on reverse logistics (1995-2005). International Journal of Production Research, 46(4), 1099-1120. doi:10.1080/00207540600943977

Sampierl, R., Collado, C., \& Lucio, P. (2012). Metodologia de pesquisa (за ed.). São Paulo, SP: McGrawHill.

Santos, A. S. F., Agnelli, J. A. M., \& Manrich, S. (2004). Tendências e desafios da reciclagem de embalagens plásticas. Revista Polímeros, 14(5), 307-312. doi:10.1590/S0104-14282004000500006

Seo, E. S. M., \& Fingerman, N. N. (2011). Sustentabilidade na gestão de resíduos sólidos: panorama do segmento eletroeletrônicos. InterfacEHS: Revista de Saúde, Meio Ambiente e Sustentabilidade, 6(3), 3-15.

Silva Filho, C. R., \& Soler, F. D. (2012). Gestão de resíduos sólidos: O que diz a lei. São Paulo, SP: Trevisan Editora

Silveira, G., \& Chang, S. (2010). Cell phone recycling experiences in the United States and potential recycling options in Brazil. Waste Management, 30(11), 2278-2291. doi:10.1016/j.wasman.2010.05.011

Sistema Nacional de Informações sobre a Gestão de Resíduos Sólidos. (2015). Acordo setorial de embalagens em geral. Recuperado de http://www.sinir.gov.br/web/guest/embalagens-em-geral

Sluisveld, M., \& Worrell, E. (2013). The paradox of packaging optimization: A characterization of packaging source reduction in the Netherlands. Resources, Conservation and Recycling, 73, 133-142. doi:10.1016/j.resconrec.2013.01.016

Souza, M., Paula, M., Souza-Pinto, H. (2012). O papel das cooperativas de reciclagem nos canais reversos pós-consumo. RAE-Revista de Administração de Empresas, 52(2), doi:10.1590/So03475902012000200010.

Thorpe, B., Kruszewska, I., \& McPherson, A. (2004). Extended producer responsibility: a waste management strategy that cuts waste, creates a cleaner environment and saves taxpayers money. Clean Production Action. Somerville, MA. Recuperado de: https:// www.cleanproduction.org/static/ee_images/uploads/resources/ EPRtoolkitColourFinal.pdf

Toffel, M., Stein, A., \& Lee, K. (2008). Extending producer responsibility: An evaluation framework for product take-back policies. Harvard Business School Working Paper, 9, 1-26.

Tojo, N. (2004). Extended producer responsibility as a driver for design change: Utopia or reality? (Dissertação de doutorado, Lund University, Sweden).

Yoshida. C. (2012). Competência e as diretrizes da PNRS: Conflitos e critérios de harmonização entre as demais legislações e normas. In A. Jardim, C. Y. M. Yoshida, \& J. V. Machado Filho, Política nacional, gestão e gerenciamento de resíduos sólidos (pp. 3-36). Barueri, SP: Editora Manole. 